\title{
Comparison of J5 Vaccinates and Controls for Incidence, Etiologic Agent, Clinical Severity, and Survival in the Herd Following Naturally Occurring Cases of Clinical Mastitis
}

\author{
D. J. Wilson, ${ }^{\star}$ Y. T. Grohn,† G. J. Bennett,† R. N. González,† Y. H. Schukken,† and J. Spatzł \\ *Department of Animal, Dairy and Veterinary Science, Utah State University, Logan 84321 \\ †Department of Population Medicine and Diagnostic Sciences, Cornell University, Ithaca, NY 14850 \\ $\ddagger$ Animal Health Centre, Te Aroha, New Zealand, 3320
}

\begin{abstract}
Holstein dairy cattle in 3 commercial herds were randomly allocated to J5 vaccination $(\mathrm{n}=251)$ or untreated control $(\mathrm{n}=306)$ groups. There were 221 new cases of clinical mastitis (CM) affecting 120 cows. Coliform mastitis cases had a higher percentage of severe quarter swelling or signs of systemic illness among control cows but not among J5 vaccinates, in comparison to noncoliform cases. Culling or death from CM affected 13 controls (4.3\%) and 4 vaccinates (1.6\%), with losses occurring earlier in lactation among controls, a higher hazard (probability of a cow dying on each day of lactation) for controls than vaccinates. The J5 vaccination was significantly associated with protection from culling for mastitis among the 15 Klebsiella cases; 2 out of $10(20 \%)$ Klebsiella-infected controls were culled and 0 out of 5 vaccinates were culled. Cows in second lactation were at reduced hazard of culling for mastitis compared with older animals, even when adjusting for effects of J5 vaccination. When all CM cases (including subsequent new cases during the same lactation and multiple quarters or pathogens within the same cow on the same day) were evaluated, for the 221 cases of $\mathrm{CM}$, the rate was significantly higher among vaccinates than controls ( 0.10 and 0.07 cases $/ 30 \mathrm{~d}$ in milk, respectively). This was because J5 vaccinates had more subsequent new cases of CM in the same cow than controls. Pathogens isolated, which included mainly environmental bacteria, were not different among J5 vaccinates and controls. Immunization with J5 was associated with protection against severe clinical coliform mastitis signs, culling, and death loss from CM but not with any reduction in overall CM.
\end{abstract}

Key words: clinical mastitis, bovine mastitis, dairy cattle, immunology

Received March 2, 2007.

Accepted May 23, 2007.

${ }^{1}$ Corresponding author: David.Wilson@usu.edu

\section{INTRODUCTION}

Coliform mastitis caused by Escherichia coli, Klebsiella spp., Enterobacter spp., and Citrobacter spp. IMI is an important disease complex of dairy cattle (Wilson et al., 1997; Hogan et al., 1999; Wenz et al., 2001). Milk loss, clinical mastitis (CM) including abnormal milk and necessity for treatment, and death of cattle can result from coliform mastitis (Jackson and Bramley, 1983; Wenz et al., 2001). Vaccines developed using the J5 core antigen of coliform bacteria have been in use for approximately $15 \mathrm{yr}$ (González et al., 1989; Cullor, 1991). Associations between J5 vaccination and various measures of clinical severity of CM have been studied infrequently for naturally occurring cases of CM. Reduction of CM in vaccinates compared with controls has been reported as 70\% (Cullor, 1991), 80\% (González et al., 1989), 72\% (González et al., 1996), and 75\% (Hogan et al., 1992). In one study, when J5 vaccination was administered at drying-off, $4 \mathrm{wk}$ later, and 1 to 7 DIM following calving, CM reduction was 93\% (González et al., 1996). Use of survival (time to event) analysis to evaluate $\mathrm{J} 5$ vaccination and associated time until the events of CM onset, culling, or death has not been previously reported. Time to event analysis is valid, because it precisely accounts for the time at risk for each animal (Fleming and Lin, 2000).

Naturally occurring cases of bovine CM were studied among J5 vaccinates or controls on 3 commercial dairy farms. Measures of incidence, pathogen(s) isolated, clinical severity, and time until CM onset, culling, or death were evaluated for differences between the 2 groups.

The objectives were to evaluate the association of a 2-dose dry-cow J5 vaccination program (administered at dryoff and 21 to $28 \mathrm{~d}$ before expected calving date) with $\mathrm{CM}$ incidence, pathogen(s) isolated, clinical severity, and time until culling or death in comparison with unvaccinated control cows in 3 commercial dairy herds.

\section{MATERIALS AND METHODS}

Three dairy farms milking Holstein cows in New York State participated in the study. The mean lactating 
herd sizes were 275, 330, and 630 lactating cows. Milk production in each herd was approximately $11,364 \mathrm{~kg}$ $(25,000 \mathrm{lb})$ per cow per lactation. All 3 herds were milked in fully automated milking parlors. Premilking and postmilking application of germicidal teat dip and cleaning of teats before milking were carried out by milkers on all 3 farms. Bulk tank milk SCC less than $250,000 / \mathrm{mL}$ were consistently achieved. None of the herds had any cows with Streptococcus agalactiae or Mycoplasma mastitis, and Staphylococcus aureus mastitis was at low levels ( $\leq 3 \%$ of cows) in each herd. A large amount of historical milk culture data demonstrated that the herds had predominantly environmental types of IMI causing mastitis before the study began.

\section{Criteria for Inclusion in Study}

Cows having completed at least 1 previous lactation were eligible for inclusion in the study, conducted for 20 mo. Cows were either excluded or provisionally enrolled on the day of dryoff, when they started the approximately 60 -d dry period before beginning the next lactation at calving. Any cow whose expected dry period was less than $45 \mathrm{~d}$ or greater than $75 \mathrm{~d}$ was excluded. Any cow whose actual dry period was outside of the above range was excluded after calving. Cows with signs of any detectable illness including but not limited to CM at time of dryoff or with any of the last 3 monthly individual-cow SCC before dryoff greater than $1,000,000 / \mathrm{mL}$ were excluded. Animals with major traumatic damage to the end of one or more teats were excluded. Cows were randomly allocated as J5 bacterin vaccinates or controls.

Enrolled cows were blocked into groups of 10 animals, with 5 cows randomly assigned to the vaccinated group and 5 to the control group, 1 block for cows ending their first lactation and another block for those ending their second or higher lactation. Within each 10-cow block of 2 groups, the mean for age-, season-, and fat-corrected 305-d mature-equivalent milk production for the 5 vaccinated cows had to be within $10 \%$ of the mean 305-d mature equivalent milk production for the 5 control cows.

The J5 vaccinations (Merial Ltd., Duluth, GA; 2-mL dosage) were administered at the time of dryoff and again 21 to $28 \mathrm{~d}$ before the calving due date. The route of administration was supramammary injection, near the supramammary lymph node. Control cows did not receive any sham vaccination.

\section{Reasons for Exclusion of Some Initially Enrolled Animals}

After cows were provisionally enrolled at the beginning of their dry period; the herd owners could remove a limited number of cows from the study at their discretion as per the study agreement. Each farm removed some animals for a total of 34 cows removed from the study during the dry period, resulting in actual enrollment of 711 cows, 374 controls; and 337 vaccinates. There were 154 enrolled cows, 68 controls, and 86 vaccinates lost or excluded from the study. Exclusions included 41 cows that had no recorded CM during the study, had no milk samples collected but that were later found to have strong evidence of having had CM when records of all cows were reviewed on Dairy Comp 305. Twenty-two of these cows (11 controls, 11 vaccinates) had a disease event described as CM during lactation, and the remaining 19 cows (10 controls, 9 vaccinates) had a disease or antibiotic treatment event that had a strong possibility of having been CM recorded on Dairy Comp 305. They were excluded, because they had no CM data or samples collected according to the study protocol but were not CM-free animals.

Other reasons for exclusion were as follows: 20 cows died during the dry period (10 controls, 10 vaccinates); 27 aborted (16 controls, 11 vaccinates); 21 were sold (13 controls, 8 vaccinates); 9 were dry longer than 75 $\mathrm{d}$ (4 controls, 5 vaccinates); 28 vaccinates were not given their second vaccination; 4 did not have postcalving blood samples collected as per protocol (2 controls, 2 vaccinates); 3 were enrolled, but no other records of the cows survived, thus they were lost to follow up (2 controls, 1 vaccinate); and 1 vaccinate was discovered after enrollment to have had an SCC test > $1,000,000 / \mathrm{mL}$.

All cases of CM occurring during the first 200 DIM or until the cow was confirmed pregnant were included. Clinical mastitis cases contracted after pregnancy were confirmed or after 200 DIM were not studied, because the effects of J5 on CM have been reported to be primarily in early lactation (Hogan et al., 1992). However, cows were monitored for whether they were sold, died, or completed lactation until the end of lactation. Some cows had multiple CM episodes in the same quarter over time. Any such episode that occurred within $5 \mathrm{~d}$ of the end of treatment (or end of milk withholding) was considered a chronic case of mastitis. Any episode that occurred from 6 to $14 \mathrm{~d}$ after recovery from the earlier episode was considered a chronic case if the same etiologic agent was isolated from both episodes. If a different mastitis pathogen was isolated or the episode occurred more than $14 \mathrm{~d}$ after recovery, this constituted a new CM case. When results were tabulated, there were 9 chronic cases out of 230 cases of $\mathrm{CM}$ (3.5\%), including 1 chronic coliform, an $E$. coli. Therefore, chronic CM cases were excluded from analysis, and all new cases meeting the above criteria were studied. 


\section{Measurement Validation and Standardization and Microbiology}

Training and standardization for CM detection, use of a cowside scale for clinical severity, and aseptic sample collection was provided to milking personnel at the beginning of the study. Clinical mastitis severity was scored as follows: 1 = abnormal milk, normal quarter; $2=$ abnormal milk, mild quarter swelling; $3=$ abnormal milk, severe quarter swelling; 4 = abnormal milk, and cow showed signs of systemic illness (off feed, fever, depression, sunken eyes). Milk samples were aseptically collected for microbiological culture at onset of any episodes of CM [mastitic quarter(s) sampled] and frozen at $-4^{\circ} \mathrm{C}$. Samples were transported once each week to our microbiology laboratory for culture according to protocols recommended by the National Mastitis Council (Hogan et al., 1999). Results of culture were defined as mixed pathogens when 2 or 3 types of bacteria other than Staph. aureus were isolated; mixed pathogens could therefore include a total of 3 or 4 types of bacteria if one was Staph. aureus. Contamination was defined as the isolation of more than 3 types of bacteria other than Staph. aureus.

\section{Production and Disease Information}

Lactation number, DIM at onset of each new case of CM, and survival days until dry, sold, or died were collected for all cows and stored electronically in Dairy Comp 305. The primary reasons why cows died or were sold were also recorded electronically. Quarter(s) with $\mathrm{CM}$ and clinical severity scores were recorded on paper forms at the farm. Mastitis pathogens were isolated, and results were recorded at the Quality Milk Production Services Central Laboratory (Ithaca, NY).

\section{Statistical Analysis}

Statistical analyses included $\chi^{2}$ (PROC FREQ) and Fisher's exact test (PROC FREQ) in SAS 8.2. Two survival (time to event) analysis techniques were also used. The life table method, the Kaplan-Meier estimator with log-rank and Wilcoxon tests, was used to test J5 vaccination as the only explanatory variable for association with time until culling because of mastitis as the primary reason (PROC LIFETEST). Cox's proportional hazards regression method was used to test several other explanatory variables (covariates) simultaneously for their association with time until culling for mastitis (PROC PHREG). For comparison of CM among all controls and vaccinates, the entire population of study cows was tested. For comparison of infection with specific pathogens among controls and vaccinates, only the population of cows with CM was tested. Evaluation of time until events of CM, infection with particular agents, subsequent new cases of CM, culling, or death used survival (time to event) analysis of all study cows.

The Kaplan-Meier method (PROC LIFETEST) calculates the probability that the event of interest occurs at a time greater than or equal to the start time of each interval:

$$
\mathrm{h}(\mathrm{t})=\text { VACC } .
$$

The initial Cox's proportional hazards model (PROC PHREG) tested was:

$$
\begin{gathered}
\mathrm{h}(\mathrm{t})=\mathrm{h}(0) \text { EXP }(\text { VACC + LACT + DIM } \\
+ \text { PRODDIFF + PREMEAN + SEVERITY } \\
+ \text { PATHOGEN + BOOSTTODUE } \\
\text { + BOOSTTOCALVE })
\end{gathered}
$$

where $\mathrm{h}(\mathrm{t})=$ probability of culling for mastitis within time $t$ for cows surviving until beginning of $t ; h(0)=a$ baseline hazard function; EXP(VACC + LACT + DIM $+\ldots)=$ a linear function of a set of fixed covariates, which are exponentiated; VACC $=\mathrm{J} 5$ vaccinate or control; LACT = lactation number 2, 3, or fourth-plus; DIM = DIM at onset of CM (censored at 200 DIM if the cow never got CM); PRODDIFF = mean milk production during $14 \mathrm{~d}$ before CM onset (PREMEAN) subtracted from mean milk production $21 \mathrm{~d}$ following end of treatment following CM [POSTMEAN; e.g., if PREMEAN = $45 \mathrm{~kg}(100 \mathrm{lb})$ per day and POSTMEAN $=41 \mathrm{~kg}(90 \mathrm{lb})$, PRODDIFF $=-4 \mathrm{~kg}(-10 \mathrm{lb})]$; SEVERITY $=4$ levels of cowside severity scale of CM described earlier; PATHOGEN = etiologic pathogen isolated from CM, including negative or no case; BOOSTTODUE = days from J5 booster to due date of expected calving; and BOOSTTOCALVE = days from J5 booster to date of actual calving.

\section{RESULTS}

The final study population consisted of 557 lactations (306 controls and 251 vaccinates). There were 13 cows that completed 2 lactations during the study.

\section{Culling and Death Loss}

Number of cows culled and the hazard of cows being culled over time were studied (Table 1 ). There were 13 cows culled with mastitis as the primary reason, 10 controls (3.3\%), and 3 vaccinates (1.2\%). This was a significantly higher number of culls, with culling occurring earlier in lactation, among controls $(P=0.10$, time to event analysis, log-rank and Wilcoxon tests; Table 1, Figure 1). The number of animals that were 
Table 1. Comparison of cows leaving the herd among J5 vaccinates and controls

\begin{tabular}{lcc}
\hline & \multicolumn{2}{c}{ Vaccination status } \\
\cline { 2 - 3 } & J5 vaccinates & $\begin{array}{c}\text { Controls } \\
(\mathrm{n}=306)\end{array}$ \\
Reason for leaving heard & $(\mathrm{n}=251)$ & $10(3 \%) *$ \\
Culled for mastitis & $3(1 \%)$ & $76(25 \%)$ \\
Culled for all reasons & $67(27 \%)$ & $3(1 \%)$ \\
Died from clinical mastitis & $1(0.4 \%)$ & $16(5 \%)$ \\
Died from all causes & $11(4 \%)$ & $2 / 10(20 \%) * *$ \\
Culled for Klebsiella mastitis & $0 / 5(0 \%)$ & .
\end{tabular}

*Significantly different from vaccinates as categorical event, $\chi^{2}$ $(P=0.10)$ and time to event analysis, log-rank and Wilcoxon tests $(P=0.10)$.

**Significantly different from vaccinates as categorical event, Fisher's exact test $(P=0.04)$ and time to event analysis, log-rank and Wilcoxon tests $(P=0.004)$.

either culled for mastitis or died as a result of CM was also studied as a combined outcome. There were 13 controls (10 culled, 3 died; $4.3 \%$ ) and 4 vaccinates (3 culled, 1 died; $1.6 \%$ ) that were lost due to culling or dying after mastitis. The hazard of these types of loss from CM was greater, with losses occurring earlier in lactation, among controls $(P=0.07$, time to event analysis, log-rank and Wilcoxon tests).

Mean and median DIM when culled for mastitis were 171.4 and 152, respectively, for controls and 182.6 and 206 for vaccinates. Culling for mastitis was also evaluated as a categorical variable (culled or not culled for mastitis) among vaccinates and controls and was again found more common among controls $\left(P=0.10, \chi^{2}\right)$. There were 143 cows culled for all reasons combined, 76 controls $(24.8 \%)$ and 67 vaccinates $(26.7 \%)$. There were 4 cows that died from CM ( 3 controls, 1 vaccinate) and 27 total cows that died from all reasons combined, 16 controls $(5.2 \%)$ and 11 vaccinates $(4.4 \%)$. Neither culling for all reasons nor death were different among

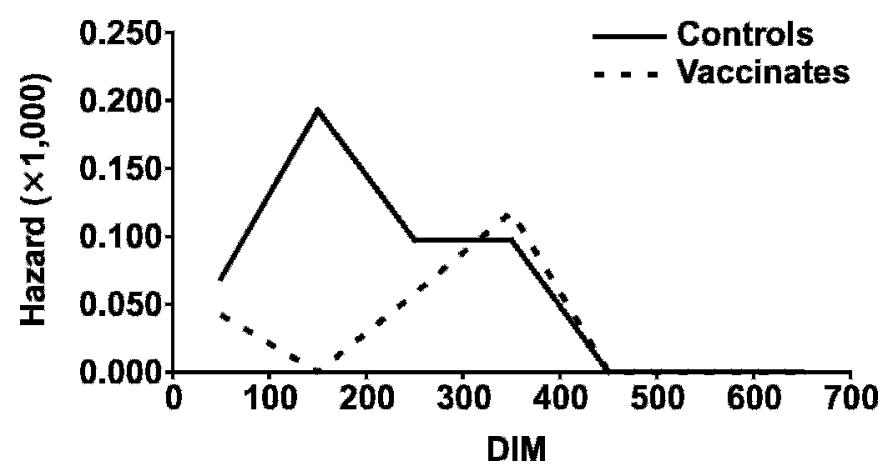

Figure 1. Shape of the hazard for cows being culled with mastitis as the primary reason. Significantly greater hazard of culling for mastitis among controls than for $\mathrm{J} 5$ vaccinates, time to event analysis, and log-rank and Wilcoxon tests $(P=0.10)$. vaccinates and controls according to survival (time to event) analysis or $\chi^{2}$.

Cox's proportional hazards regression model (PROC PHREG) was used to test whether other factors besides J5 immunization were also associated with likelihood of cows being culled with mastitis as the primary reason. The final model had likelihood ratio $\chi^{2} 22.1,3 \mathrm{df}, P$ $<0.0001$ (Table 2). Factors associated with postmastitic culling when adjusting for the effects of the others were J5 vaccination (protective, hazard ratio 0.27 ), second lactation compared with third or fourth-plus lactation cows (protective, hazard ratio 0.18), and having contracted at least 1 case of $\mathrm{CM}$ (risk factor, hazard ratio 7.64; all $P \leq 0.05$, likelihood ratio $\chi^{2}$, Table 2).

The association between etiologic agents of $\mathrm{CM}$ and likelihood of leaving the herd was further evaluated. Cows contracting Klebsiella CM were more likely to be culled with mastitis as the primary reason when this was considered simply as a relationship between those 2 categorical variables. There were 15 cows (that had a total of 21 quarters infected) with Klebsiella CM, and 2 of them (13.3\%) were culled; $2.0 \%$ of the rest of the cows were culled for mastitis $(P=0.04$, Fisher's exact test). However, J5 vaccination was significantly associated with protection from culling for mastitis among the 15 Klebsiella cows; 2 out $10(20 \%)$ of Klebsiellainfected controls were culled ( $P=0.04$, Fisher's exact test showing increased risk of culling with Klebsiella), and 0 out of 5 vaccinates were culled (Table 1). Survival (time to event) analysis was also performed to evaluate the hazard of culling on any particular day during lactation. Cows with Klebsiella CM were at greater hazard of culling and being culled earlier in lactation for mastitis than all other cows $(P=0.004$, time to event analysis, log-rank and Wilcoxon tests; Table 1). However, once again, this increased hazard was for control cows $(P=$ 0.001 , time to event analysis, log-rank and Wilcoxon tests), because J5 vaccinates had no increase in the hazard of culling with Klebsiella CM (Figure 2).

\section{Severity of $\mathrm{CM}$}

When all mastitis pathogens were evaluated together, neither vaccination status nor etiologic pathogen was associated with CM clinical severity. Because $25 \%$ of the cells in the $\chi^{2}$ had expected values less than 5 , Fisher's exact test was used. There was a trend that vaccinates had more mild cases $(56 \%)$ than controls (47\%), but the difference was not significant $(P=0.25$, Fisher's exact test).

However, of the coliform CM cases (E. coli, Klebsiella, and Enterobacter) for which severity scores were recorded ( $n=59$ ), a higher percentage of cases had severity scores 3 and 4 than noncoliform cases $(\mathrm{n}=122 ; P=$ 
Table 2. Cox's proportional hazards regression model evaluating factors affecting the hazard of cows being culled with mastitis as the primary reason

\begin{tabular}{lcccccc}
\hline Variable $^{1}$ & DF & $\begin{array}{c}\text { Parameter } \\
\text { estimate }\end{array}$ & SE & $\chi^{2}$ & $P$ & Hazard ratio \\
\hline J5 VACC & 1 & -1.306 & 0.661 & 3.900 & 0.048 & $0.27^{2}$ \\
LACT2 & 1 & -1.718 & 0.774 & 4.933 & 0.026 & 0.18 \\
MAST & 1 & 2.033 & 0.661 & 9.462 & 0.002 & 7.64 \\
\hline
\end{tabular}

${ }^{1} \mathrm{~J} 5 \mathrm{VACC}=\mathrm{J} 5$ vaccinated cows; LACT2 $=$ second-lactation cows (cows in first lactation were not eligible for study; this is in comparison with cows in third or fourth-plus lactations); MAST = cows that contracted at least one case of clinical mastitis.

${ }^{2}$ Ratio of the hazard of culling because of mastitis for cows with this characteristic compared with cows not having this characteristic.

0.04, Fisher's exact test). Those scores correspond to abnormal milk with severe quarter swelling and signs of systemic illness, respectively. The increased severity of CM caused by coliforms was most evident in the unvaccinated control cows. Control cows $(\mathrm{n}=92)$ had a nonsignificant tendency to have more severe CM signs (scores 3 and 4) among their coliform cases $(P=0.15$, Fisher's exact test), whereas J5 vaccinates $(\mathrm{n}=89)$ had no trend toward more severe coliform cases than those caused by other pathogens $(P=0.37$, Fisher's exact test).

\section{Incidence of CM}

During the study period of $606 \mathrm{~d}$, there were 437 lactations without a case of CM, 247 controls and 190 vaccinates. Clinical mastitis was contracted at least once during 120 study lactations ( 1 of 119 cows to contract CM completed 2 study lactations and contracted $\mathrm{CM}$ in both lactations), 59 controls and 61 vaccinates. The likelihood of contracting at least 1 case of CM was not different among vaccinates (24.3\% had CM) and

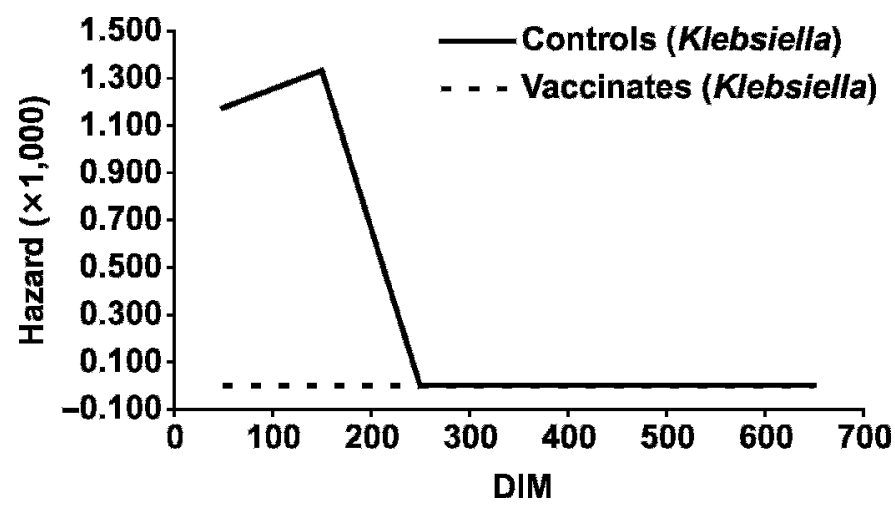

Figure 2. Shape of the hazard for cows with Klebsiella being culled with clinical mastitis as the primary reason. Klebsiella clinical mastitis cases, J5 vaccinates, and controls. Among cows with Klebsiella, there was a greater hazard of culling for mastitis among controls than for J5 vaccinates $(P=0.001$, time to event analysis, logrank and Wilcoxon tests). controls $\left(19.3 \% \mathrm{CM} ; P=0.15, \chi^{2}\right)$. However, there were 46 subsequent episodes of $\mathrm{CM}$ that met criteria for new cases, which together with the 120 initial cases of CM resulted in 166 new cases of CM, 76 controls and 90 vaccinates. In addition, there were 46 additional quarters (for a total of 2 to 4 quarters per cow) affected with $\mathrm{CM}$ on the same day and 9 quarters infected by 2 pathogens on the same day, accounting for a total of 221 cases (quarter-pathogen-days of onset) of $\mathrm{CM}$ among the 166 onset days, 105 cases in controls and 116 in vaccinates. When all 221 cases of $\mathrm{CM}$ were evaluated, vaccinates $(46.2 \% \mathrm{CM})$ were more likely to contract $\mathrm{CM}$ than controls $\left(34.3 \% \mathrm{CM} ; P=0.03, \chi^{2}\right)$. A milk culture sample was collected from 204 of the 221 new cases of CM (99 controls, 105 vaccinates). Etiologic pathogens isolated from CM cases are shown in Table 3. Proportion of mastitis pathogens isolated was not different among vaccinates and controls $\left(P=0.23, \chi^{2}\right)$.

At calving, 21 of the 557 cows $(3.8 \%)$ had $\mathrm{CM}$ in 31 quarters (10 controls, 21 vaccinates). Vaccinates $(8.4 \%$ $\mathrm{CM}$ ) were more likely to have $\mathrm{CM}$ at calving than controls $\left(4.0 \% \mathrm{CM} ; P<0.01, \chi^{2}\right)$ Pathogens isolated from these $31 \mathrm{CM}$ cases at calving were as follows: 2 no

Table 3. Etiologic agents of 204 clinical mastitis cases among J5 vaccinates $(\mathrm{n}=251)$ and controls $(\mathrm{n}=306)^{1}$

\begin{tabular}{lcc}
\hline & \multicolumn{2}{c}{ Vaccination status } \\
\cline { 2 - 3 } Pathogen & $\begin{array}{r}\text { J5 vaccinates } \\
(\mathrm{n}=105)\end{array}$ & $\begin{array}{c}\text { Controls } \\
(\mathrm{n}=99)\end{array}$ \\
\hline No pathogen isolated & 10 & 18 \\
Escherichia coli & 27 & 15 \\
Klebsiella sp. & 8 & 13 \\
Streptococcus sp. & 26 & 26 \\
Staphylococcus aureus & 9 & 8 \\
CNS & 6 & 7 \\
Arcanobacterium pyogenes & 7 & 4 \\
Enterobacter sp. & 3 & 0 \\
Yeast & 1 & 0 \\
Gram-positive bacilli & 2 & 0 \\
Fungi & 1 & 6 \\
Mixed pathogens & 5 &
\end{tabular}

${ }^{1}$ No significant differences, $\chi^{2}(P=0.23)$. 
pathogen isolated ( $6.5 \%$ of cases; 2 controls), 2 E. coli (6.5\%; 1 control, 1 vaccinate), 13 nonagalactiae streptococci (Streptococcus spp.; 41.9\%; 4 controls, 9 vaccinates), 2 Staph. aureus (6.5\%; 2 vaccinates), 1 CNS (3.2\%; 1 vaccinate), 8 Arcanobacterium pyogenes ( $25.8 \%$; 3 controls, 5 vaccinates), 1 gram-positive bacillus $(3.2 \% ; 1$ vaccinate), and 2 mixed pathogens $(6.5 \%$; 2 vaccinates). Proportion of mastitis pathogens isolated was not different among vaccinates and controls $(P=$ $\left.0.40, \chi^{2}\right)$.

Total days at risk for $\mathrm{CM}$ were 79,636 d: 36,300 d for the 251 vaccinates and 43,336 d for the 306 controls. Mean days at risk for CM were 145 and 142 for vaccinates and controls, respectively. The incidence rate of new cases of CM (all pathogens combined) can be evaluated in several different ways. If the definition of CM is that each cow can contract only 1 case on a given day, even if it is infected in multiple quarters, multiple pathogens, or both, the rate for the $166 \mathrm{~d}$ with onset of CM was 0.06 cases/30 DIM. Rates for controls and vaccinates, respectively, were 0.05 and 0.07 cases $/ 30$ DIM. The rate of all new CM cases was higher among vaccinates according to survival (time to event) analysis $(P=0.005$, log-rank and Wilcoxon tests). If the definition of CM is that each cow can contract a case in multiple quarters, with multiple pathogens per quarter, or both, the rate for the 221 new cases of CM was 0.08 cases/30 DIM. Rates for controls and vaccinates, respectively, were 0.07 and 0.10 cases/30 DIM, again higher among vaccinates according to survival (time to event) analysis ( $P=0.01$, log-rank and Wilcoxon tests).

Incidence rates of CM caused by individual pathogens ( $n=204$, allowing for more than one pathogen in more than one quarter on the same day of onset) per 30 DIM were as follows: no pathogen isolated 0.011, $E$. coli 0.017 , Klebsiella 0.008, Streptococcus spp. 0.020, S. aureus 0.006 , CNS $0.005, A$. pyogenes 0.005 , Enterobacter 0.002 , yeast 0.002 , gram-positive bacilli $<0.001$, fungi $<0.001$, and mixed pathogens 0.005 . There were no differences among vaccinates and controls in new infection rates of $\mathrm{CM}$.

\section{DISCUSSION}

In contrast with previous reports, J5 vaccination was not associated with reduced rates of coliform $\mathrm{CM}$ or any agents of CM in the present study. Different studies of J5 vaccines over time have used different manufacturers, sometimes different adjuvants, and vaccines vary in number of inactivated bacteria and thus the amount of core antigen. However, there was still evidence of benefit from the use of J5 because of the significant association with protection against culling or death loss of cows because of mastitis.
The J5 vaccination was associated with survival advantages regardless of etiology of CM. Vaccinates were less likely to be culled as a direct result of mastitis or to be lost from the herd because of the combined reasons of culling or dying from mastitis. The hazard of being culled from mastitis was especially lower among vaccinates in early lactation. The association of J5 with reduced culling from $\mathrm{CM}$ was still present when adjusting for the other significant effects of being a second lactation animal (protective) or having contracted at least 1 case of CM (risk factor). An apparent tendency for J5 vaccinates to be less likely to be culled following CM was also noted in an earlier report (González et al., 1989).

The only etiologic agent of CM strongly associated with risk of culling for mastitis was Klebsiella and that was only for control cows. Vaccinates with Klebsiella CM were less likely to be culled for mastitis than controls (none of the Klebsiella cases in vaccinates were culled). Survival (time to event) analysis showed that control cows with Klebsiella CM were also at greater hazard of culling for mastitis earlier in lactation, but J5 vaccinates did not have this increased hazard. Efficacy of J5 in reducing the rate of CM cases of Klebsiella has been previously reported (González et al., 1989, 1996), but that was not observed in this study, and survival was not investigated in those earlier studies. Rats challenged orally with Klebsiella pneumoniae have been reported to have significantly increased survival among J5 vaccinates (Cross et al., 2001). However, there are no other published findings regarding J5 and association with survival of Klebsiella CM cases. The survival advantage from either culling or dying from mastitis reported here for J5 (approximately $4.5 \%$ for controls vs. $1.5 \%$ for vaccinates) is similar to that reported previously for Re17 mutant-vaccinated cows (approximately 2.5 vs. $1.0 \%$; McClure et al., 1994).

There were more CM cases with systemic illness or severe quarter swelling among coliform-infected controlsbut not among coliform-infected J5 vaccinates. This agrees with a previous study reporting that less clinical severity of naturally occurring cases of CM was observed among J5 vaccinates (González et al., 1989).

We found that J5 was not associated with reduced CM, regardless of severity, which was somewhat surprising. Risk of infection with particular mastitis pathogens and the infection rates with the pathogens, including coliforms, were not affected by J5 vaccination in this study. Survival analysis showed that time during lactation until onset of $\mathrm{CM}$ was not associated with J5 vaccination either. This contradicts the findings in earlier reports of reduced cases of CM among J5 vaccinates (González et al., 1989, 1996; Cullor 1991; Hogan et al., 1992). Those previous studies have all used 3 doses of J5 vaccination, usually at time of dryoff, some- 
time during dry period, and around the time of calving. Earlier work using only 2 doses of coliform mastitis vaccination has shown less efficacy against CM, but those studies have also used Re17 mutant Salmonella Typhimurium bacterin instead of J5 (McClure et al., 1994; Scott et al., 1996). Current study results raise the question of whether a third dose of J5 following calving may be beneficial, considering that all of the above studies using 3 doses had greater efficacy in reducing total cases of CM. Nevertheless, the $2 \%$ reduction in culling as a result of $\mathrm{CM}$ and the $2.5 \%$ reduction in culling and death loss combined (approximately a two-thirds reduction of the above losses compared with controls) represent a major benefit from use of J5 vaccination.

\section{CONCLUSIONS}

Immunization of dairy cattle with J5 was associated with reduced likelihood of culling because of mastitis or the combined categories of culling and dying as a result of the disease. This was present even when adjusting for the other significant effects of being a second lactation animal (protective) or contracting at least 1 case of CM (risk factor). There was a strong association of J5 vaccination with protection against Klebsiella cases being culled for mastitis. Within J5 vaccinates, there was no tendency for coliform cases to be more clinically severe than those caused by other agents, but there was among control cows. We found that J5 was not associated with reduced rates of coliform mastitis or all types of CM; this was unexpected and contrasted with results of previous studies. There was still demonstrated benefit from the use of J5 because of the association with reduced culling or death loss of cows from mastitis.

\section{ACKNOWLEDGMENTS}

This work was funded by grants from USDA award number 98-5204-6489. We appreciate the cooperation of the owners and personnel of the participating dairy farms and the staff of the Canton Northern Regional
Laboratory, the Cobleskill Eastern Regional Laboratory, and the Ithaca Central Regional Laboratory of the Quality Milk Production Services. Published concurrently as Utah Agricultural Experiment Station paper number 7887, 2007.

\section{REFERENCES}

Cross, A. S., S. M. Opal, H. S. Warren, J. E. Palardy, K. Glaser, N. A. Parejo, and A. K. Bhattacharjee. 2001. Active immunization with a detoxified Escherichia coli J5 lipopolysaccharide group B meningococcal outer membrane protein complex vaccine protects animals from experimental sepsis. J. Infect. Dis. 183:1079-1086.

Cullor, J. S. 1991. The Escherichia coli J5 vaccine: Investigating a new tool to combat mastitis. Vet. Med. (Praha) 86:836-844.

Fleming, T. R., and D. Y. Lin. 2000. Survival analysis in clinical trials: Past developments and future directions. Biometrics 56:971-983.

González, R., J. Cullor, D. Jasper, T. Farver, R. Bushnell, and M. Oliver. 1989. Prevention of clinical coliform mastitis in dairy cows by a mutant Escherichia coli vaccine. Can. J. Vet. Res. 53:301-305.

González, R. N., D. J. Wilson, H. O. Mohammed, P. M. Sears, A. L. Rivas, and S. G. Campbell. 1996. A placebo-controlled trial of an Escherichia coli J5 bacterin and the ribotyping-based assessment of coliform bacteria diversity on a dairy farm. Pages $277-280$ in Proc. 19th World Buiatrics Congr., Edinburgh, Scotland. Br. Cattle Vet. Assoc., Frampton-on-Severn, UK.

Hogan, J. S., R. N. González, R. J. Harmon, S. C. Nickerson, S. P. Oliver, J. W. Pankey, and K. L. Smith. 1999. Pages 85-111 in Laboratory Handbook on Bovine Mastitis. NMC Inc., Madison, WI

Hogan, J. S., K. L. Smith, D. A. Todhunter, and P. S. Schoenberger. 1992. Field trial to determine efficacy of an Escherichia coli J5 mastitis vaccine. J. Dairy Sci. 75:78-84.

Jackson, E., and J. Bramley. 1983. Coliform mastitis. In Pract. 5:135-146.

McClure, A., E. Christopher, W. Wolff, W. H. Fales, G. F. Krause, and J. Miramonti. 1994. Effect of Re-17 mutant Salmonella Typhimurium bacterin toxoid on clinical coliform mastitis. J. Dairy Sci. 77:2272-2280.

Scott, H. M., J. M. Sargeant, M. J. Ireland, K. E. Leslie, K. D. Lissemore, D. F. Kelton, and B. A. Mallard. 1996. Efficacy of an Re17 mutant Salmonella Typhimurium core antigen vaccine under field conditions. Pages 281-284 in Proc. 19th World Buiatrics Congr., Edinburgh, Scotland. Br. Cattle Vet. Assoc., Framptonon-Severn, UK.

Wenz, J. R., G. M. Barrington, F. B. Garry, K. D. McSweeney, R. P. Dinsmore, G. Goodell, and R. J. Callan. 2001. Bacteremia associated with naturally occurring acute coliform mastitis in dairy cows. J. Am. Vet. Med. Assoc. 219:976-981.

Wilson, D. J., R. N. González, and H. H. Das. 1997. Bovine mastitis pathogens in New York and Pennsylvania: Prevalence and effects on somatic cell count and milk production. J. Dairy Sci. 80:2592-2598. 